\title{
Knowledge, attitudes and practices of mothers on breastfeeding in urban environment in dakar
}

\begin{abstract}
Introduction

The relevance and benefits of breastfeeding are well established and developing countries have every interest in having a policy of strengthening their societies. Yet very few studies have been carried out on this subject.
\end{abstract}

Objectives: To assess the knowledge, attitudes and practices of mothers on breastfeeding

Material and method: This is a prospective study involving 510 mothers, based on individual interviews from November 19, 2015 to April 26, 2016.

Results: $37.3 \%$ had received information about breastfeeding during pregnancy. Exclusive breastfeeding was more practiced by educated mothers $(\mathrm{p}=0.01)$. Colostrum was given to the child in $95.3 \%$. Nearly half of the mothers introduced a additional diet before 6 months. Breastfeeding on demand was practiced by $82.5 \%$ of mothers. The position of the Madonna was adopted by $99.4 \%$ of the mothers. Almost all mothers were unaware that breast milk could be preserved. The beneficial role of milk in the prevention of allergies, diabetes and obesity was only known by $1.2 \%$ of mothers.

Conclusion: A lack of knowledge and some attitudes not in line with recommendations were noted regarding the introduction and continuation of breastfeeding. The involvement of health authorities and medical and paramedical personnel could improve knowledge and practice.

Keywords: Breastfeeding, knowledge, attitude, practice

\author{
Volume 7 Issue 3 - 2018
}

\author{
Mamour Gueye, Magatte Mbaye, Moussa \\ Diallo, Mame Diarra Ndiaye Gueye, Omar \\ Gassama, Adboul Aziz Diouf, Mouhamadou \\ Mansour Niang, Alassane Diouf, Jean Charles \\ Moreau \\ Obstetric gynecology Unit, Pikine National Hospital, Sénégal
}

Correspondence: Moussa Diallo, Obstetric and Gynecology, Cheikh Anta DIOP of Dakar, Pikine National Hospital,Thiaroye Camp, Dakar, Sénégal, Tel 3385300 7I, Fax 3385300 69, Email moussadiallo25@hotmail.com

Received: March 31, 2018| Published: May 09, 2018

\section{Introduction}

Following the report of an expert committee mandated by the World Health Organization (WHO), WHO recommended protecting, promoting and supporting exclusive breastfeeding for six months and ensuring the provision of safe and adequate complementary foods, with continued breastfeeding up to two years of age or beyond. ${ }^{1}$ In developed countries, such as France, the percentage of breastfeeding mothers when they left maternity was $66.3 \%$ in 2007 and the duration of breastfeeding was short ${ }^{2}$ with an estimated median duration of ten weeks. ${ }^{3}$ In Canada, the breastfeeding rate at birth was $85 \%$ in 2003 (39\% exclusively). ${ }^{4}$ In African countries such as Tunisia and Morocco, breastfeeding rates were $94.4 \%$ in 2008 (1.9\% continued exclusive breastfeeding until 6 months) and $97.5 \%$ in $2006(15 \%$ exclusively). ${ }^{5,6}$ From 1990 to 2004, exclusive breastfeeding in subSaharan Africa increased from $15 \%$ to $32 \%$ in West Africa and from $4 \%$ to $22 \%$ in Central Africa. Despite this upward trend, exclusive breastfeeding remains low and a public health priority in many countries. ${ }^{7}$ In Senegal, $99.8 \%$ of women breastfeed their children, and only $34 \%$ of children breastfeed exclusively up to 6 months according to the 2005 Demographic and Health Survey. ${ }^{8}$ In order to comply with World Health Organization recommendations and to ensure optimal growth and health of the child, it is essential that mothers have a good knowledge of breastfeeding and related factors. The main objective of this work was to assess mothers' breastfeeding knowledge, attitudes and practices.

\section{Methodology}

This was a prospective study conducted over a period of 5 months from November 19, 2015 to April 26, 2016. We collected all patients who had given birth in the facility who had chosen exclusive breastfeeding for their children and who had agreed to complete the questionnaire. Only 510 patients clearly answered the questions. We excluded patients whose language we did not understand. It included a survey conducted through interviews using a semistructured questionnaire with open or closed questions, single or multiple choice. We had targeted for our study the lactating women who came to the post-natal consultation at the Philippe Maguilen Senghor Health Center. Was included in the study all parturient seen at the post-natal consultation accompanied by his child and accepting the conditions of the interrogation. The data was collected through interviews that lasted an average of 15 minutes. Verbal consent was obtained from women who had agreed to participate in the survey. They were reassured about the confidential and anonymous nature of the work. The survey was led by a female doctor who spoke in the local language (Wolof) and in French. The latter was oriented on the content of each item of the questionnaire. A preliminary survey was conducted with 10 mothers before validating the questionnaire. The questionnaire consisted of two parts: the socio-demographic and obstetrical characteristics and the part relating the knowledge of attitudes and practices of breastfeeding. Two questions related to the positions taken during breastfeeding. The first question did not have 
an answer pattern. The correspondence of the description made by the mothers was searched among the 6 positions of the question which followed (Figure 1). During the interview, the woman interviewed directly indicated the position she adopted using pictograms that were shown to her.

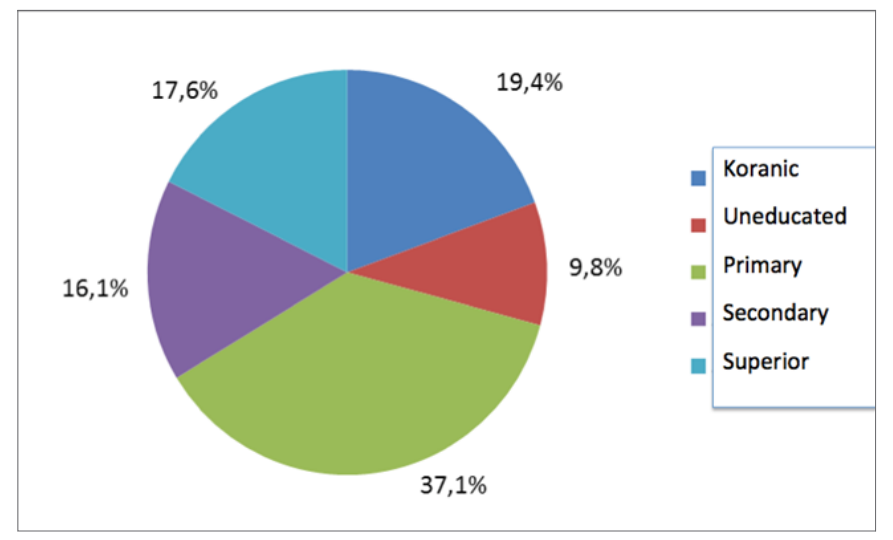

Figure I Distribution of mothers by level of education.

\section{Result}

\section{Socio-demographic characteristics}

We surveyed 510 women and all agreed to answer, a $100 \%$ participation rate. The average age of mothers was 27 years old. The age range between 26 and 30 years was the most represented. The most representative level of education was the primary level in $37.1 \%$ of mothers. A proportion of $19.4 \%$ had a Koranic education and $17.6 \%$ had a university level. Only $9.8 \%$ of our patients were uneducated. Almost all mothers were married (96.9\%). Unoccupied mothers accounted for $47.3 \%$ of the sample (Figure 1).

Follow-up of the pregnancy: Pregnancies were followed by midwives $(78.8 \%)$ and doctors $(21.2 \%)$. The majority of women were followed in a public center $(97.7 \%$ ) while $2.7 \%$ had antenatal visits in a private center.

Delivery mode: Delivery was by vaginal route for most women $(88.6 \%, \mathrm{n}=452)$, of whom 274 had an episiotomy with a frequency of $60.6 \%$.

Information on breastfeeding during pregnancy monitoring: Only one-third of women (37.3\%) had received information about breastfeeding during pregnancy. More than half of the women followed by a gynecologist $(56.5 \%)$ had received breastfeeding information during prenatal follow-up, while less than one-third of the patients followed by a midwife had received this information (32), $1 \%)$ with a statistically significant difference $(\mathrm{p}=0.0001)$. Nearly half of the patients (43.7\%) had just given birth to their first child.

Breastfeeding of other children: To the question "Have you breastfed your other children? Only 3 of the women who had ever given birth (n $=287$ ) answered with a "no" rate of $1 \%$. For those who had breastfed their child, exclusive breastfeeding was practiced in $96.8 \%$.

\section{Knowledge, attitudes and practices}

Breastfeed mode: At the time of the survey, 8 out of 10 women (80\%) had exclusive breastfeeding, $18.4 \%$ had mixed breastfeeding and $1.6 \%$ had used artificial breastfeeding.
Delay of begining breastfeed: The majority of mothers (77\%) had started breastfeeding beyond 2 hours after delivery, $21 \%$ between 30 minutes and 2 hours and only $2 \%$ within half an hour of delivery. More than 3 out of 4 patients had breastfed beyond 2 hours. Only 2 patients who had a caesarean section had breastfed within 2 hours after delivery.

Knowledge of colostrum: Colostrum, the first milk, was known to almost all $(98.4 \%)$ of the mothers. On the other hand, nine women $(1.6 \%)$ had no knowledge of it.

Use of colostrum: The vast majority of nurses $(95.3 \%)$ gave colostrum to their newborns. Twenty-three mothers (4.5\%) thought that colostrum was harmful and did not administer it to their child. They were all primiparous. A mother could not give her child's colostrum because he was in an incubator.

Other foods received in addition to breast milk during the first 6 months: During this period, just over half of children (56.5\%) were breastfeeding only; $29.2 \%$ of the children received water in addition to breast milk (Table 1).

Table I Distribution of food received in addition to breast milk

\begin{tabular}{|c|c|c|}
\hline Food in addition to breast milk & Effective & Percentage \\
\hline No supplement & 288 & 56,5 \\
\hline Water & 149 & 29,2 \\
\hline Water, honey, butter & 19 & 3,7 \\
\hline Water, porridge & 11 & 2,2 \\
\hline Water, commercial milk & 9 & $\mathrm{I}, 8$ \\
\hline Vegetables, water & 4 & 0,8 \\
\hline $\begin{array}{l}\text { Water, commercial milk, porridge, } \\
\text { vegetables }\end{array}$ & 5 & I \\
\hline Mash, commercial milk & 2 & 0,4 \\
\hline Water, porridge, vegetables & 2 & 0,4 \\
\hline Water, honey & 2 & 0,4 \\
\hline Milk from the trade & 2 & 0,4 \\
\hline Honey & 2 & 0,4 \\
\hline Mash, vegetables & I & 0,2 \\
\hline Decoctions & 1 & 0,2 \\
\hline Decoctions, honey, butter & 1 & 0,2 \\
\hline Water, porridge, honey & I & 0,2 \\
\hline Water, commercial milk, porridge & 1 & 0,2 \\
\hline Trade milk, water & I & 0,2 \\
\hline $\begin{array}{l}\text { Trade milk, vegetables, porridge, honey, } \\
\text { butter }\end{array}$ & I & 0,2 \\
\hline Vegetables, porridge, water & 1 & 0,2 \\
\hline Honey, butter & I & 0,2 \\
\hline
\end{tabular}

Age of introduction of food: To the question, "At what age should food be introduced? $66.3 \%$ of mothers responded "beyond 6 months" (Figure 1). Before 6 months, multiparous and uneducated mothers were more likely to add a dietary supplement (butter, commercial milk, honey or water). The professional activity was not correlated 
with the addition of foods in addition to breast milk before 6 months.

Assistance with breastfeeding and number of feedings per day: Mothers who breastfed their children on demand were the most represented $(82.5 \%)$. The majority of mothers $(62.9 \%)$ did not receive any assistance to breastfeed their children. For those who benefited from it, the person helping could be the mother, the mother-in-law, the cousin, the sister, the aunt or the husband.

Positions adopted during breastfeeding and best timing of breastfeeding: The mothers's description of their breastfeeding positions was the position of the madonna (or lullaby) in $99.4 \%$. For $65.9 \%$ of mothers, the best time to breastfeed was the moment of crying, compared to $31.4 \%$ when they started to show signs of awakening. Two percent of the patients felt that breastfeeding was preferential during sleep.

Breastfeed's complications: For the majority of mothers (70\%), breastfeeding was good until the day of the interview; $23.9 \%$ had waterlogging and $6.1 \%$ had crevasses. We found a statistically significant link between parity and the occurrence of complications of breastfeeding. Indeed, primiparity was more complicating than multiparity $(p=0.012)$. The level of education was not correlated with the occurrence of complications of breastfeeding.

Attitude to adopt in case of cracks: Almost all mothers (91.2\%) had no idea of the attitude to adopt in front of a breast crevice, for $1.4 \%$, it was necessary to suspend breastfeeding on the affected side. Thirtyeight mothers $(5.5 \%)$ had proposed various attitudes.

Minimum recommended duration of breastfeeding: For $65.7 \%$ of mothers, the minimum recommended duration of breastfeeding was 24 months; $19.2 \%$ of mothers estimated that this duration was 18 months.
Food during breastfeed: More than half of the mothers $(61.7 \%)$ thought that it was possible to eat everything during the period of breastfeeding.

Knowledge of the signs of effective sucking: For $53.5 \%$ of women, ample sucking and no break were signs of effective sucking (Table 2).

Table 2 Distribution of mothers according to their knowledge of signs of effective sucking

\begin{tabular}{lll}
\hline $\begin{array}{l}\text { Signs of characteristic sucking sign of } \\
\text { feeding effectiveness }\end{array}$ & Effective & Pertcentage \\
\hline Ample suction and no break & 273 & 53,5 \\
Slow, steady suction rate & 145 & 28,4 \\
Mouth wide open, lips rolled up & 53 & 10,4 \\
Child well awake with open eyes & 5 & $\mathrm{I}$ \\
Child well awake with open eyes. & $\mathrm{I}$ & 0,2 \\
Don't know & 49 & 9,6 \\
\hline
\end{tabular}

Preservation of breast milk: The majority of mothers $(82 \%)$ did not know that breast milk could be preserved. Only $18 \%$ replied in the affirmative.

Benefits of breastfeeding: The rate of knowledge of the benefits of breastfeeding was considered low. In terms of weight gain and infant protection, mothers' responses were affirmative in $27.3 \%$ and $37.3 \%$, respectively. The other benefits were ignored in almost all cases as shown in Table I. The benefits of breastfeeding for the mother in terms of body weight and absence of menstruation were reported by only $13.9 \%$ and $18 \%$ of mothers, respectively. Virtually all mothers (98.3\%) believed that breast milk was rich enough to feed their children (Table 3 ).

Table 3 Distribution of mothers according to their knowledge of the benefits of breastfeeding $(N=510)$

\begin{tabular}{|c|c|c|c|}
\hline Benefits of breastfeeding & Yes & No & Do not know \\
\hline \multicolumn{4}{|l|}{ For the children } \\
\hline Improvement of intellectual and psychomotor development of the child & $43.30 \%$ & - & $56.70 \%$ \\
\hline Infectious protection of the child & $37.30 \%$ & $0.40 \%$ & $62.40 \%$ \\
\hline Faster weight gain than bottle & $27.30 \%$ & $4(0.8 \%)$ & $367(72 \%)$ \\
\hline Prevention against allergies & $0.20 \%$ & - & $99.80 \%$ \\
\hline Prevention against obesity & $0.20 \%$ & - & $99.80 \%$ \\
\hline Prevention against diabetes & $0.20 \%$ & - & $99.80 \%$ \\
\hline \multicolumn{4}{|l|}{ For the mother } \\
\hline Absence of rules & 18 & 14.3 & 67.6 \\
\hline Long-term weight loss & 13.9 & 26.5 & 59.6 \\
\hline Decreased risk of breast cancer & 9 & 0.2 & 90.8 \\
\hline Economic & 3.5 & 0.6 & 95.9 \\
\hline Reduced risk of genital infections & - & 0.2 & 99.8 \\
\hline Reduced risk of anemia & - & 0.2 & 99.8 \\
\hline
\end{tabular}




\section{Discussion}

\section{Knowledge of breastfeeding}

Information on breastfeeding: In our series, $37.3 \%(\mathrm{n}=190)$ of mothers had received breastfeeding information during pregnancy follow-up; and these patients were for the most part followed by gynecologists. The same is true for Roida who reported in a series of 200 mothers an awareness that had interested $37.5 \%$ of women. ${ }^{6}$ In the study of Diagne et al. 6 out of 44 mothers said they had never received any advice for feeding their child. ${ }^{8}$ In other studies this information was delivered mainly by the entourage as shown by Hassani's study. ${ }^{9}$ Lack of breastfeeding information provided to mothers by caregivers is an important factor in early cessation of breastfeeding. The study by Blyth et al. showed a significant relationship between information and the degree of prenatal support received and duration of breastfeeding. ${ }^{5}$

Signs of an effective succion: In accordance with the signs of characteristic sucking, which indicates suckling efficacy, as described in the literature, ${ }^{10}$ only $6.5 \%$ of mothers had an accurate knowledge of suckling efficiency. In fact, $51.8 \%$ of the mothers considered that the sign of an efficient sucking was ample sucking and the baby should not pause and $26.5 \%$ that the sucking rate should be slow and regular.

Beneficts of breastfeeding: According to data from the literature, the beneficial role of breast milk is indisputable. ${ }^{4}$ The majority of mothers did not know the benefits of breastfeeding for their health. It is undeniable that the role of health professionals remains crucial. This is only possible during prenatal visits through sensitization sessions, childbirth preparation and parenting classes; the provision of brochures for mothers.

\section{Practices and mother's attituds}

Delay of breastfeed begining: The World Health Organization recommends starting breastfeeding within half an hour of birth. ${ }^{4}$ Early breastfeeding after delivery was noted as beneficial for breastfeeding duration, while delayed breastfeeding appears to be an earlier risk factor for weaning. ${ }^{11}$ Our study found that a small proportion of mothers $(0.2 \%)$ gave breast milk less than 30 minutes postpartum, $21.8 \%$ between 30 minutes and 2 hours, and $78 \%$ after 2 hours. The reasons given for this delay are the repair of the episiotomy, the late milky rise, the rest of the mother and the child. As for colostrum (first milk), $98.4 \%$ of mothers were known, unlike the Hassani study, where $70.6 \%$ of mothers had no idea of the value of colostrum. ${ }^{9}$ He was thrown by $4.5 \%$ of the mothers contrary to the study of Diagne ${ }^{8}$ where no woman had discarded colostrum.

Dietary attitudes during breastfeeding: The vast majority of patients $(61.7 \%)$ knew they did not need to eat a particular diet and $17.1 \%$ of women felt that breastfeeding helps them lose weight faster in the first 6 months of life. With an energy yield of milk production estimated between 80 and $85 \%$, this corresponds to an increase in needs of about $630 \mathrm{kcal} /$ day. These energy needs corresponding to breastfeeding can be partly covered by a mobilization of accumulated fat during pregnancy. Weight loss is, in fact, highly variable from one woman to another, and is usually limited to the first three months of breastfeeding. In women in good nutritional condition, it is on average $800 \mathrm{~g} /$ month $(27 \mathrm{~g} /$ day $)$. If we admit that this weight loss has an energy equivalent of $6.5 \mathrm{kcal} / \mathrm{g}$, it corresponds to the use of $176 \mathrm{kcal}$ per day on average. In this case, the energy requirement is reduced by $455 \mathrm{kcal} /$ day, which is easily covered by the increase in food consumption. ${ }^{12}$
Food diversification: According to WHO recommendations, dietary diversification should now begin at 6 months of age. ${ }^{4}$ This has the effect of reducing atopic manifestations of the child. ${ }^{12}$ Dietary diversification delayed after the age of 6 months is now part of the usual recommendations for the primary prevention of allergy, according to the European Society of Pediatric Gastroenterology, Hepatology and Nutrition (ESPGHAN), introduction of the egg, fish and peanut after 1 year. The American Academy of Pediatrics suggests a later introduction for certain foods: cow's milk protein at 12 months, egg at 24 months, and peanut, nuts and fish at age $3 .^{12}$ In our study, earlier diversification was more often the attitude of multiparas and was therefore not necessarily related to ignorance of the youngest.

Frequency of feedings and foods given in addition to the breast: As for the number of times breastfeeding per day, WHO and the United Nations International Children's Emergency Fund (UNICEF) encourage breastfeeding at the request of the child through the "Ten Conditions for Successful Breastfeeding" published in a joint document written in 1989. This breastfeeding on demand was adopted by $82.5 \%$ of mothers in our series. In the Hassani study, mothers had breastfed on demand at a rate of $32 \% .^{9}$ As for the difficulties encountered during breastfeeding, milk insufficiency was identified as the main cause of cessation of breastfeeding in studies carried out in Brazil, Tunisia and Morocco, with respectively $55 \%$ and $44.5 \%$. and $23.8 \%{ }^{9}$

\section{Conclusion}

The practice of breastfeeding has undeniable advantages for the child and the mother in both the short and long term. From our study, it follows that it remains a common practice in Senegal. However, insufficient education and cultural practices that are not in keeping with the international recommendations that are sometimes very ingrained could take away its primary virtues. For this purpose, it is essential, as for contraception, to introduce it during the prenatal consultations by the nursing staff.

\section{Acknowledgements}

None.

\section{Conflict of interest}

Authors declare that their is no conflict of interest.

\section{References}

1. OMDL S. Stratégie mondiale pour l'alimentation du nourrisson et du jeune enfant: durée optimale de l'alimentation au sein exclusive. Consultation d'experts sur la durée optimale de l'alimentation au sein exclusive. 2001.

2. Courtoisie E, Tysio S, Lacombe M. Les facteurs associés à la poursuite de l'allaitement maternel jusqu'à 6 mois La revue de la Sage-Femme. 2012;11:280-83.

3. Siret VCC, Boileau P, Castetbon K, et al. Facteurs associés à l'allaitement maternel du nourrisson jusqu'à 6 mois à la maternité de l'Hopital AntoineBèclère. Archives de pédiatrie. 2008;15(7):1167-73.

4. Beaudry M, Chiasson S, Lauzière J. Biologie de l'allaitement: Presses de l’Université du Québec; 2006.

5. Bouanene I, Elmahamdi S, Bouslah A, et al. Connaissances et pratiques des femmes de la région de Monastir (Tunisie) concernant l'allaitement. La revue de la santé de la Méditerranée orientale. 2010;16:879-85. 
6. Roida M, Hassi A MMF. Les pratiques de l'allaitement maternel à la maternité universitaire de Marrakech. Journal de pédiatrie et de puériculture. 2010;23(2):70-5.

7. Traoré $\mathrm{M}$, Sangho $\mathrm{H}$, Diagne $\mathrm{M}$, et al. Facteurs associés à l'allaitement maternel exclusif chez les mères d'enfants de 24 mois à Bamako. Revue santé publique. 2014;26:259-65.

8. Diagne Gueye NR, Diack Mbaye A, Dramé M, et al. Connaissances et pratiques de mères sénégalaises vivant en milieu rural ou suburbain sur l'alimentation de leurs enfants, de la naissance à l'age de 6 mois. Journal de pédiatrie et de puériculture. 2011;24(4):161-6.

9. Hassani A, Barkat A, Souilmi F, et al. La conduite de l'allaitement maternel. Etude prospective de 211 cas à la maternité Souissi de Rabat. Journal de pédiatrie et de puériculture. 2005;18(7):343-8.
10. Arenz S, Ruckerl R, Koletzko B, et al. Breastfeeding and childhood obesity: A systematic review. Int J Obes Relat Metab Disord. 2004;28(10):1247-56.

11. Wagner S, Kersuzan C, Cojard S, et al. Durée de l'allaitement maternel en France selon les caractéristiques des parents et de la naissance. Résultats de l'étude longitudinale française Elfe. Bulletin Epidémiologique Hebdomadiare. 2011;29:522-32.

12. Turk D. Allaitement maternel: les bénéfices pour la santé de l'enfant et de sa mère. Archives de pédiatrie. 2005;12(S3):145-65. 